\title{
URBAN SUSTAINABILITY INDICATORS FOR CARIBBEAN SMALL ISLAND DEVELOPING STATES
}

\author{
Tracey C.A. Beard-Sylvester ${ }^{1 *}$ \\ ${ }^{1}$ Faculty of Engineering, The University of the West Indies, Trinidad \\ ${ }^{1}$ Email: tracey.beard@my.uwi.edu*(Corresponding author)
}

\begin{abstract}
This research seeks to develop an urban sustainability framework specific to Caribbean Small Island Developing States (SIDS). This is relevant given the reality that Caribbean SIDS are becoming increasingly urbanised. The three most urbanised countries within the Caribbean region; namely, the Bahamas, Trinidad and Tobago and Suriname are more than 70 percent urbanised. If the built environment within urban areas is developed in an unsustainable manner this can result in a number of negative outcomes. For example, a major challenge faced in Caribbean SIDS is that of disaster risk and management due to the location of human settlements and critical infrastructure in low lying coastal lands.

If more sustainable outcomes are to be attained in the face of increased urbanisation, there is a need for a change in the way spatial planning is practiced. Indicators can provide planners with an empirical basis for the examination and review of the relevant plans and policies which guide the way in which planning is practiced. There exist a number of urban indicator frameworks, which suggest useful indicators including the World Bank Urban Sustainability Framework (USF) and the Inter-American Development Bank Emerging and Sustainable Cities Initiative (ESCI). These two frameworks are critically examined and with the use of Trinidad as a case study island, the ways in which indicators can be useful in efforts toward increased urban sustainability within SIDS is discussed.
\end{abstract}

Keywords: Caribbean, Small Island Developing States, Urban sustainability, Indicators.

https://doi.org/10.47412/WRXT3932

\section{Introduction}

Small Island Developing States (SIDS) were first recognized in 1992 at the United Nations Conference on Environment and Development (UNCED) [25]. These countries share similar characteristics which pose challenges to sustainable development. These include but are not limited to the following [23]: (i) Relatively small geographical size with insular physical barriers within and relative to other countries; (ii) Relatively small but rapidly growing populations; (iii) Vulnerability to natural hazards and other global environmental challenges such as those resulting from climate change and sea level rise and; (iv) The location of human settlements and critical 
infrastructure on low lying coastal lands. This paper highlights urban sustainability issues faced within Caribbean SIDS with particular reference to the island of Trinidad.

At least 59 per cent of the population in SIDS now live in urban areas [23] and within the Caribbean, levels or urbanization are relatively high [11]. The three most urbanized countries in the Caribbean region were identified by [11] as the Bahamas (79 per cent urban), Trinidad and Tobago (72 per cent urban) and Suriname (76 per cent urban).

In Trinidad and Tobago, there are at least twenty-two areas which can be classified as urban; seven of these with population ranges of between $20000-40000$ plus persons and fifteen with population ranges of between $5000-20000$ persons [1]. In addition to already high levels of urbanization in Caribbean territories, the rate at which urbanization is taking place is expected to increase significantly. For example, by 2050, the rate of urbanisation in Antigua and Barbuda, Barbados and the Bahamas is expected to triple and by 2050, the rate of urbanisation in Antigua and Trinidad and Tobago is expected to increase six-fold [11]. Additionally, Trinidad and Tobago is expected to experience a seven-fold increase in urban land cover [11].

There is also a prevalence of primate cities and coastal/port cities, many of which are also located in Low Elevation Coastal Zones (LECZs) [11]. Increased concentration of persons in these cities necessitates the consideration of climate change (CC) realities and the integration of disaster risk reduction strategies within our spatial development strategies (SDS).

In the Caribbean, many important economic activities such as fishing, tourism, manufacturing and agriculture take place in the coastal zone. It is a place where people both live and make a living. In many of the Caribbean islands, especially those which are volcanic in origin, much of the land is mountainous, leaving mostly coastal lands available for development. The development of large scale hotels for example, especially if done in an unregulated manner, contributes to the degradation of these coastlines and their associated features such as coral reefs, mangroves and beaches. Importantly, these features serve as the first line of defence for many islands in the event of the occurrence of natural hazards such as hurricanes, storm surges and tsunamis. Once coral reefs or beaches have been degraded this leaves the entire coastal zone up to mountainous areas exposed and vulnerable to the effects of natural hazards. In the face of climate change, these hazards are expected to increase in frequency and intensity and the economic losses as a result are expected to be significant. For example, the cost of climate change for the Caribbean is estimated at US\$6 billion per year through to 2050 [3] and the annual cost to Caribbean SIDS due to inaction on increased hurricane damages, loss of tourism revenue, and infrastructure damages, is projected to a total of US $\$ 22$ billion annually by 2050 and US $\$ 46$ billion by 2100 [3].

Trinidad's urban centres include the city of Port of Spain, the city of San Fernando and the borough of Chaguanas. Port of Spain (POS) serves as the country's main retail, administrative and political centre [17]. The most pressing development challenges for POS along with its wider Metropolitan area, including the regional corporations of Diego Martin and San Juan/Laventille include limited land space for new development, urban sprawl and severe traffic congestion particularly during peak user hours. Other significant challenges include the continued growth of informal settlements which is linked to issues of insecure land tenure, lack of access to basic urban services such as clean water, sewerage systems and solid waste management, high levels of unemployment and increasing crime [22]. The typical location of informal settlements in environmentally sensitive 
upper, middle and lower watershed areas, along with authorised built development in these areas are partly responsible for more frequent and severe flooding incidents in POS.

The literature notes that 76 percent of Trinidad's population resides in urban centres which has been generating a demand for land for housing and construction material and aggregate sourced from quarries near watershed areas and forested areas [13]. Additionally, increased permitted and unpermitted built development along hillsides is associated with deforestation and degradation of the country's watersheds. Estimates indicate that nearly one quarter of Port of Spain's Metropolitan area (65 000 persons) reside in unauthorised ‘squatter' residences [2].

This is a major contributor to the flooding events experienced in the Metropolitan Port of Spain area, as existing drainage systems are inadequate for accommodating the volume of runoff emanating from hillside areas [2]. Additionally, the threat of sea level rise associated with climate change can compound issues of flooding in the future [2].

Some of the impacts of climate change which are expected to most affect SIDS such as Trinidad and Tobago include rising sea levels as well as the increased occurrence of and more intense natural hazards such as hurricanes, tropical cyclones, floods and droughts [11]. The InterAmerican Development Bank [7], notes that sea level rise as a result of climate change can affect the following in Trinidad: (i) Sewerage and drainage systems in Port of Spain; (ii) Salinisation of coastal aquifers; (iii) Low lying coastal areas, particularly on the west coast of the island where there is high population density and considerable economic development and; (iv) Coastal erosion, especially where the shores consist of flat profiles and consist of unconsolidated material in beach areas.

\section{Urban Sustainability and the Use of Sustainability Indicators}

Whereas there was a focus on economic development post World War II (Sachs 1999), a new paradigm of sustainable development emerged in the 1970s with a focus on human well-being and global equity for future generations. The term 'sustainable development' was first coined in the 1970s [9] and has since been popularized by the Bruntland Commission Report (BCR) of 1987 [24]. The report defined sustainable development as "meeting the needs of the present without compromising the ability of future generations to meet their own needs". Satterthwaite [15] contends that the term 'sustainable development', when applied to cities, refers to whether two goals can go together: (i) to ensure that cities meet the needs of the present (by being healthy, enjoyable, resilient places to live and work without (ii) compromising the ability of future generations to meet their own needs (by ensuring that consumption and production levels relative to local, regional and global resources are not disproportionate).

The literature agrees that whilst historically, cities have enabled social and economic advancement [15], they have also contributed to a number of 'failures' in development. These include urban poverty, the rapid growth of informal settlements, congestion, declining infrastructure, lack of funding for basic service provision and unsustainable levels of resource use [15]. Even in the face of these negatives and with the increasing proportions of populations living and working in cities; they do have the potential to allow a combination of high living standards with relatively low resource consumption that can enable urban sustainability [15]. Satterthwaite [15] suggests that this can be achieved through a form of municipal governance that is more innovative and accountable and through effective partnerships with civil society groups. 
Further to this, Satterthwaite also suggests that a number of characteristics associated with the city can be advantageous for achieving greater levels of sustainability. He notes that the concentration of people, enterprises, motor vehicles and their wastes that exists in cities provides a number of opportunities to potentially de-link a high quality of life from high levels of resource consumption. Such opportunities include the following:

(i) Higher density housing can decrease energy use, water use, carbon dioxide emissions and the carbon footprint of material used for consumption per dwelling;

(ii) A high density and concentration of people lowers the cost per household and enterprise for the provision and maintenance of infrastructure, pollution control and the management of hazardous wastes;

(iii) Economies of scale and proximity for reducing risks of disasters and greater capacity among city dwellers to pay for or contribute to the cost of these;

(iv) Close proximity of a large number of water consumers provides a greater scope for recycling or directly re-using wastewaters and;

(v) Cities enable a greater number of journeys to be made by walking or cycling and greater feasibility for greater use of a high quality public transport service.

Verrest et al [26] have noted that over the past few decades, due to significantly increased urbanisation, "urban matters have re-emerged as an area of international academic and policy attention”. Evidence of such international attention includes: (i) the 2009 United Nations Human Settlements Programme (UN-Habitat) Global Report on Human Settlements entitled 'Planning Sustainable Cities'; (ii) the Sustainable Development Goals (SDGs) (specifically goal number 11, 'to make cities inclusive, safe, resilient and sustainable' (United Nations 2015) and; (iii) the 'New Urban Agenda' adopted by the United Nations (UN) General Assembly in December 2016.

\subsection{Defining Urban Sustainability}

Complementary to this increased academic and policy attention on urban matters, there exists a plethora of literature with respect to definition and use of the term urban sustainability. Many writings identify sustainability as having four major dimensions, namely; social, economic, environmental and a governance or institutional aspect [16], [12]. In other literature, the meaning of the terms 'urban sustainability' and 'sustainable city' as opposed to 'sustainable urbanisation' and 'sustainable urban development' are clarified. For example, the terms 'urban sustainability' and 'sustainable city' may be used to refer to environments where suitable conditions exist that would allow for sustainability. Such conditions include the "proper use of resources, protection of the natural environment, least possible use of non-renewable resources, economic growth and variety, community self-confidence, individual welfare, and satisfaction of basic human needs" [16]. In contrast, 'sustainable urbanization' and 'sustainable urban development' apply to a dynamic process towards attaining the suitable conditions, where equal attention is given to the four dimensions of sustainability [16].

Placing the focus on Caribbean SIDS, Mycoo [10] has identified four key elements of urban sustainability relevant to Caribbean SIDS, with respect to the attainment of SDG number 11 . These 
are: (i) Effective and efficient urban governance, (ii) Market instruments and regulations, (iii) Integrated spatial and infrastructure planning and mainstream ecosystem services in planning and (iv) New smart technologies.

Many authors [10], [5], [6], [18] have emphasised the importance of good governance and the role of local government in efforts toward increased urban sustainability. The World Bank [18] suggests that a city is enabled to achieve sustainability by using two important methods, which its Urban Sustainability Framework (USF) calls enabling dimensions: (1) good governance and integrated urban planning processes; and (2) sound management of city finances to ensure financial sustainability.

Finally, James et al. [8] posits 'circles of sustainability' in which sustainability intersects with other social conditions such as resilience, liveability, adaptation, innovation and reconciliation as basic conditions of positive social life.

\subsection{Sustainability Indicators}

\subsubsection{Sustainability Indicators - Definition and Use}

Integral to the urban planning process is plan monitoring, evaluation and the use of related indicators. Rosales [14] notes that over the last few decades "different methods, techniques and instruments for urban sustainable assessment that seek to figure out how cities can become more sustainable have emerged". These include the use of indicators "as they provide a solid foundation for decision making.....and contribute to the building of sustainable systems where development and environment can be integrated" [14].

The literature further suggests that it is now increasingly common practice globally to monitor and evaluate the impacts and outcomes of urban plans [21]. According to UN-Habitat [21], two core and common stages included in the monitoring and evaluation of urban plans are the selection of outcome indicators along with time specific targets. Ideally, policies should be developed in unison with supportive indicators [21]. Likewise, indicators should be clearly associated with a policy or set of possible action in order to be useful.

Rosales [14], identified a set of 'urban sustainable indicators for planning' which integrated four types of indicators, namely; sustainability profile indicators, urban planning performance indicators and monitoring and assessment indicators. She argues that there is still a gap between the use of urban and sustainability indicators in plan making and in urban planning performance. She notes that if used in an integrated way, these indicators could be used for assessing and monitoring urban trends as well as measuring the impact in terms of sustainability of policies and programs. She argues that the use of sustainable indicators in "the early stages of urban planning would help advance the incorporation of sustainability goals throughout the planning process, which would, eventually, translate into sustainable cities by design” [14].

\subsubsection{Sustainability Indicators - Classification}

Existing sustainability indicators may be classed as belonging to either a first, second or third generation of indicators [4]. First generation indicators are focused on economic metrics and follow a macroeconomic approach; whereas, second generation indicators, guided by the Millennium Development Goals are more thematic and sectoral in nature. Third generation indicators, guided by the United Nations 2030 Development Agenda and the UN SDGs are considered to be more wholistic in nature with human and ecological well-being at the core. These 
indicators are used within multidimensional monitoring frameworks such as the World Council on City Data (WCCD 2016) and the UN-Habitat City Prosperity Index (2013).

\subsection{Towards a Fourth Generation of Urban Indicators}

Gomez-Alvarez et al [4] notes that despite the use of more wholistic indicators, our understanding of cities is still limited in four ways. Firstly, there is still only a partial global geographic coverage of specific regions; secondly a focus on measurement at the national level still exists; thirdly there is still only a small depiction of particular aspects of urban dynamics and fourthly there is a lack of a territorial 'geo-localised' approach. Gomez-Alvarez et al [4] advocates that there is need for need for a strong, territorial dimension into city analysis as a key factor that could enhance the accuracy in establishing urban governance. There is also need for a more localized approach to development at the city level. Gomez-Alvarez et al [4] therefore postulates that a fourth generation of urban indicators is needed to provide a broader, more people-centered approach, alongside existing monitoring frameworks.

This paper examines within the context of Caribbean SIDS, two existing frameworks for this purpose; the World Bank Urban Sustainability Framework (USF) and the Inter-American Development Bank (IDB); Emerging and Sustainable Cities Initiative (ESCI). The World Bank USF was selected as one of the most recent frameworks to be developed globally and the ESCI as it is the only indicator framework developed which is specific to the Latin America and Caribbean region.

\section{Urban Sustainability Frameworks}

\subsection{The World Bank Urban Sustainability Framework (USF) - An Overview}

The World Bank's USF is based on six dimensions; two of which are categorised as 'enabling dimensions' and the other four as 'outcome dimensions. The two dimensions which enable a city to achieve sustainability are (i) Governance and integrated urban planning and (ii) Fiscal sustainability which involves the sound management of city finances to ensure financial sustainability. Sustainable cities also demonstrate four key outcomes, which the USF terms outcome dimensions: (i) Urban economies, which demonstrate robust economic growth, prosperity, and competitiveness across all parts of the city; (ii) Natural environment and resources; (iii) Climate action and resilience and (iv) Inclusivity and quality of life [18].

Each dimension comprises a series of key focus areas that highlights characteristics that particularly impact urban sustainability [18]. These are important for cities to consider when diagnosing, measuring and enhancing their sustainability performance within the Sustainable Development Goals (SDGs) and the New Urban Agenda [18]. The importance of each focus area and the way it can be addressed is expected to vary across cities and therefore each city is expected to chart its own course toward the goals of the six dimensions by prioritizing focus areas according to its particular context and circumstances [18].

In developing the USF, the idea of resilience was incorporated into each dimension. The USF describes urban resilience as "the ability of cities, under the impact of shocks and stress, to continue to function so that the people who live and work there- especially the poor and the vulnerable- 
survive and prosper” [18]. Additionally, “Resilience focuses on improving a city’s performance against multiple hazards, rather than preventing or mitigating asset loss due to specific events" [18].

\subsection{The Inter-American Development Bank Emerging and Sustainable Cities Initiative (ESCI) - An Overview}

The ESCI utilises an integrated methodology based on three pillars, namely; environmental and climate change sustainability, urban sustainability and fiscal sustainability, for addressing the issues which hamper the sustainable growth of cities in the LAC region [6]. These three main areas can further be further grouped into 23 topics, 59 sub-topics and 120 indicators. The methodology utilises a traffic light rating criteria where red indicates performance below minimum levels, yellow indicates that improvement is required and green indicates sustainability [6].

The city of POS was selected as a pilot city for the implementation of the ESC in 2011, and the methodology can be useful as a foundation for further work on urban policy in the city. During the pilot, a rapid diagnostic assessment of the city showed with respect to environmental sustainability; issues surrounding protected areas, flooding, watershed degradation, natural disaster risk and climate change received a red rating [6]. This highlights the need for special attention to be placed in these areas.

\subsection{An Urban Sustainability Framework Specific to Caribbean SIDS}

An examination of the frameworks presented above reveals that both frameworks identified similar core areas of focus, namely; fiscal sustainability and governance, environmental and climate change sustainability as well as issues related to urban economies and quality of life. The USF presented the issues of governance and fiscal sustainability as two separate entities whilst these were grouped together under the ESCI. Issues of climate change and environmental sustainability were also grouped together in the ESCI but presented separately in the USF. Additionally, the ESCI presented a core area of urban sustainability whereas the USF addressed urban economies and quality of life issues as two separate groupings.

The USF is particularly useful within the context of this research as it can be utilised by any city wishing to contribute toward international efforts to realise Sustainable Development Goal 11 which is to "make cities inclusive, safe, resilient and sustainable" [18] [20]. The 14 indicators associated with SDG 11 are therefore named as core indicators within the USF [18]. Cities may then therefore compile multicity data sets which can "help track international progress toward SDG 11” [18].

An indicator framework specific to Caribbean SIDS can consider a number of indicators named by the World Bank USF, including the following: 'direct disaster economic loss in relation to global GDP', 'local disaster risk reduction strategies adopted and implemented in line with the Sendai Framework for Disaster Risk Reduction', 'awareness of and preparedness for natural disasters', 'critical infrastructure at risk', 'existence of adequate early warning systems with contingency plans' and 'existence of risk maps'. 
The ESCI is also pertinent to this research as it was developed specifically for use by countries within the Latin America and Caribbean region. This research hopes to build upon the existing ESCI framework whilst also recognising the Caribbean as a unique geographical space as well as the unique characteristics of SIDS as outlined earlier in section 1 . This is keeping with the call for a more localised approach of development at the city level in developing fourth generation indicators. Gleaning public perspectives on a number of issues will also be important if indicators are to be more people centred.

\section{Conclusion}

SIDS are becoming increasingly urbanised [11]. Levels of urbanisation within Caribbean SIDS are relatively high and the rate at which this urbanisation is taking place is expected to increase significantly into the future [11]. This necessitates that urgent action be taken in light of the characteristics of SIDS which pose challenges to sustainable development.

The process of urbanisation has undoubtedly contributed to a number of negative development outcomes. Despite this, the possibility of more positive outcomes can be a reality. Key to achieving positive outcomes is the existence of a form of urban governance that is effective [15], [10], [6], [18]. This is re-iterated as one of the key elements of urban sustainability relevant to Caribbean SIDS [10].

The use of indicators has been found to be useful within the context of urban planning in determining how urban areas can become more sustainable. Their use has been constantly evolving to the extent that they may be classified as belonging to a first, second or third generation of indicators [4]. Existing indicators can be developed further to include a fourth generation whose purpose would be to provide a more people centred and geo-localised approach alongside existing monitoring frameworks [4]. Finally, The ESCI and the World Bank USF were found to be suitable reference frameworks for further work on developing fourth generation indicators within the context of Caribbean SIDS.

\section{References}

[1] All-Inclusive Development Services Limited (APDSL). 2012. "National Spatial Development Plan for Trinidad and Tobago. Phase I - The Situational Analysis.”

[2] Beard, Tracey. 2013. “Sustainable Cities: The Case of Metropolitan Port of Spain.” Master's thesis. The University of the West Indies, St Augustine, Trinidad and Tobago.

[3] Bueno, Ramon, Cornelia Herzfeld, Elizabeth Stanton and Frank Ackerman. 2008. The Caribbean and Climate Change: the Costs of Inaction. United States: Tufts University.

[4] Gómez-Álvarez, D., López-Moreno, E., Bilsky, E., Ochoa, K., \& Lara, E. (2018). Indicators for Measuring Urban Sustainability and Resilience. In T. Elmqvist, X. Bai, N. Frantzeskaki, C. Griffith, D. Maddox, T. McPhearson, et al. (Eds.), Urban Planet: Knowledge towards Sustainable Cities (pp. 163-179). Cambridge: Cambridge University Press.

[5] González Couret, D. (2016) 'Urban sustainability in Latin America: challenges and perspectives’, Arquitectura and Urbanismo, 37(1), 63-69.

[6] Inter-American Development Bank (IDB). 2012. "Sustainable Port of Spain Trinidad and Tobago: Action Plan”. 
[7] Inter-American Development Bank (IDB). 2015. "Climate Change Adaptation Study: Sea Level Rise in Trinidad and Tobago

[8] James, P., Magee, L. and Manfred, S. (2015) Urban sustainability in theory and practice: circle of sustainability, New York, Routledge.

[9] Jocobus A. 2006. "Sustainable development-historical roots of the concept". Environmental Sciences, 3:2,83-96.

[10] Myсоо M. 2018. "Urban sustainability in Caribbean Small Island Developing States: a conceptual framework for urban planning using a case study of Trinidad". International Development Planning Review, 40: 2, 144 -173.

[11] Mycoo, Michelle and Michael Donovan. 2017. A Blue Urban Agenda: Adapting to Climate Change in the Coastal Cities of Caribbean and Pacific Small Island Developing States. Washington: Inter-American Development Bank.

[12] Mycoo. M. A Caribbean New Urban Agenda post-Habitat III: Closing the gaps. Habitat International 69, (2017) 68-77

[13] Mycoo, M. (2010). "Environmental policy for water resources development: A case study of Trinidad”. Saving Small Island Developing States Environmental and Natural Resource Challenges. Eds. Shyam Nath, John L Roberts and Yeti Nisha Madhoo, Commonwealth Foundation, UK.

[14] N. Rosales. Towards the modelling of sustainability into urban planning: Using indicators to build sustainable cities. Procedia Engineering 21, (2011) 641-647

[15] Satterthwaite, David. 2010. “The Role of Cities in Sustainable Development”.

[16] S.M. Rasoolimanesh, N. Badarulzaman, M. Jaafar. City Development Strategies (CDS) and Sustainable Urbanisation in the Developing World. Procedia - Social Behavioural Sciences 36, (2012) 623-631

[17] The Interplan Group Limited. 2010. "Final Draft Development Plan: A Strategic Planning Framework for Metropolitan Port of Spain.”

[18] The World Bank. 2018. Global Platform for Sustainable Cities - Urban Sustainability Framework

[19] United Nations (UN). 2016. New Urban Agenda: Quito Declaration on Sustainable Cities and Human Settlements for All. Quito: UN.

[20] United Nations (UN). 2015. Transforming our world: the 2030 Agenda for Sustainable Development. New York: UN.

[21] United Nations Human Settlements Programme (UN-Habitat). 2009. Planning Sustainable Cities: Global Report on Human Settlements, 2009. London, Sterling: Earthscan.

[22] United Nations Human Settlement Programme (UN-Habitat). 2012. Trinidad and Tobago: Port of Spain Urban Profile. Nairobi: UN-Habitat.

[23] United Nations Human Settlement Programme (UN-Habitat). 2015. Urbanisation and Climate Change in Small Island Developing States. Nairobi: UN-Habitat.

[24] United Nations. 1987. "Report of the World Commission on Environment and Development". [25] United Nations. 1992. "Report of the United Nations Conference on Environment and Development."

[26] Verrest, Hebe, Asad Mohammed and Sarah Moorcroft. 2013. “Towards a Caribbean Urban Agenda". 